\title{
JENIS-JENIS MARSUPIALIA PADA AREAL RENCANA PERKEBUNAN PALA KABUPATEN TELUK WONDAMA DAN TELUK BINTUNI
}

\section{(Marsupial Species Distribution in Nutmeg Plantation Designed Area of Teluk Wondama and Teluk Bintuni Regencies)}

\author{
Anton S. Sinery ${ }^{1,2 \bowtie}$ dan Hendrik Burwos ${ }^{2}$ \\ ${ }^{1}$ Jurusan Kehutanan, Fakultas Kehutanan Universitas Papua Manokwari, Papua Barat, \\ 98314. Tlp/Fax: +62986211065. \\ ${ }^{2}$ Pusat Penelitian Lingkungan Hidup Universitas Papua, Manokwari, Papua Barat, Amban \\ Manokwari 98313.Telp: 085244308802. \\ ${ }^{\square}$ Penulis Korespondensi: Email: anton_sineri@yahoo.com \\ Diterima: 02 Feb 2019| Disetujui: 01 Mar 2019
}

\begin{abstract}
Abstrak
Penelitian ini bertujuan untuk mengetahui keberadaan mamalia berkantung pada kawasan rencana pengembangan kopermas perkebunan Kami Nassey di Kabupaten Teluk Wondama dan Teluk Bintuni. Pengumpulan data di lapangan dilakukan selama 7 hari dengan luasan kawasan mencapai 8.000 ha meliputi Kampung Werianggi, Kampung Werabur dan Kampung Idor. Adapun status kawasan berupa areal penggunaan lain (APL) dalam bentuk hutan primer kering, hutan sekunder kering, dan semak belukar yang mana termasuk tipe ekosistem hutan dataran rendah, dan sebagian merupakan daerah bukit kapur, dan ekosistem rawa. Hasil penelitian menunjukkan bahwa kawasan ini memiliki tingkat keragaman jenis hewan mamalia berkantung yang tinggi, baik dari famili maupun jenisnya. Dari hasil survei, ditemukan 14 spesies dan 12 diantaranya merupakan jenis endemik Papua (New Guinea) dan 5 jenis masuk dalam jenis yang dilindungi oleh Kementerian Lingkungan Hidup dan Kehutanan serta 5 spesies lainnya termasuk dalam kategori daftar merah IUCN serta 2 spesies termasuk ke dalam daftar CITES Appendix II.
\end{abstract}

Kata kunci: mamalia berkantung, ekosistem hutan, perkebunan, keragaman jenis, endemis

\begin{abstract}
The aim of this research is to determine the presence of marsupial in the area of the planned development of the Kopermas Kami Nassey Plantation, Teluk Wondama and Teluk Bintuni Regencies. Data collection were took place over 7 days in an area of 8,000 ha that covered Werianggi village, Werabur, and Idor village with the status of other use areas (APL) in the form of primary dryland forest, secondary dryland forest, and shrub which were included lowland forest ecosystem, karst hill, and swamp ecosystem. The results showed that the forest had high diversity of animal species from marsupial mammals, in both family and species. The diversity of marsupialia mammals with 14 species of which 12 species have been endemic to Papua (New Guinea) and other 5 species were protected by the Ministry of Envoronment and Forestry Regulation. Another 5 species have been included in the IUCN Red List Category, and 2 species were listed in CITES Appendix II. Keywords: marsupial, forest ecosystem, plantation, species diversity, endemic
\end{abstract}




\section{PENDAHULUAN}

Tercatat kurang lebih 200 jenis mamalia darat terdapat di Papua dan 154 jenis diantaranya telah diketahui membentuk populasi-populasi besar yang meliputi jenis endemik maupun jenisjenis introduksi (Petocz 1987). Diperkirakan Papua memiliki 20.00025.000 spesies hewan yang tersusun dari 164 spesies mamalia; 329 spesies reptil dan amfibi; 650 spesies burung; 250 spesies ikan air tawar; 150.000 spesies serangga yang sejumlah diantara endemik dan dilindungi (Krey dkk. 2019). Lebih jauh disebutkan bahwa sampai saat ini telah tercatat adalah 191 jenis mamalia asli Papua yang meliputi 40 jenis endemik.

Eksistensi satwa liar dalam ekosistem dipengaruhi oleh berbagai komponen lingkungan (ekternal), selain kemampuan individu secara internal, sehingga informasi terkait jenis, populasi, sifat dan habitat mutlak dipahami secara baik dalam pengelolaan satwa liar (Sinery 2015). Menurut Dasman (1964) dalam Odum (1993), dinamika populasi satwa liar tidak hanya bergantung pada laju kelahiran (natalitas) dan kematian (mortalitas), tapi juga kemampuan satwa masuk (imigrasi) atau keluar (emigrasi) dalam dan dari populasi. Menurut Primack dkk. (2000) bahwa kisaran spesies dapat berubah akibat tanggapan yang diberikan terhadap perubahan iklim dan struktur bentangan darat (landscape), disamping kemampuan reproduksi dan adaptasi keturunan. Oleh karenanya kualitas dan kuantitas habitat sangat menentukan prospek pemanfaatan dan kelestarian satwa liar.

Keberadaan potensi tersebut saat ini diperhadapkan dengan ancaman akibat hilangnya habitat dan perburuan. Oleh karenanya berbagai upaya terus dilakukan pemerintah, pemerintah daerah dan berbagai pihak dan salah satunya diantaranya mewujudkan optimalisasi kawasan lindung sesuai KLHS RZWP3K dan KLHS Revisi RTRW Papua Barat (2013-2033) masing-masing seluas dan 39\% (laut) dan 55-60\% (teresterial berupa konservasi, mangrove, rawa, gambut, perlindungan setempat, rawan bencana, lindung geologi, PIPPIB, LP2B/KP2B, PIAPS, spiritual budaya dan NKT serta areal lainnya. Tujuan penelitian ini untuk mengetahui jenis-jenis mamalia berkantung (marsupialia) pada areal rencana pembangunan perkebunan pala Kopermas Kami Nassey Distrik Nikiwar Kabupaten Teluk Wondama dan Kampung Idoor Kabupaten Teluk Bintuni.

\section{METODE PENELITIAN}

\section{Waktu dan Tempat}

Penelitian ini berlangsung selama 2 bulan (Agustus - September 2018) dan dilaksanakan pada areal rencana perkebunan pala Kopermas Kami Nassey seluas 8.000 ha di Kampung Werianggi, Werabur dan Kampung Idor Distrik Nikiwar Kabupaten Teluk Wondama. Areal tersebut berstatus areal penggunaan lain (APL) yang mencakup hutan lahan kering primer, hutan lahan kering sekunder dan semak belukar yang terdiri atas ekosistem hutan dataran rendah, perkebukitan karts dan ekosistem rawa.

\section{Pengumpulan dan Analisis Data}

Pengumpulan data jenis dan individu kelompok mamalia dilakukan melalui survei disertai penangkapan secara langsung, pemasangan perangkap (cage 
trap dan camera trap) dan wawancara. Survei dilakukan pada areal rencana perkebunan pala khususnya lokasi persemaian pertengahan Kampung Werabur dan Werianggi, hutan dataran rendah sekitar Kampung Idoor dan areal karts sekitar Gunung Maskeri serta areal sekitar dusun sagu. Pengamatan langsung dilakukan dengan menyusuri transek pada masing lokasi pengamatan baik pada siang hari maupun malam hari. Pengamatan pada siang hari dimulai pagi hingga sore hari (jam 8.00 - 16.00), selanjutnya pada malam hari dimulai jam 20.00 sampai 23.00 WIT.

Pengumpulan data juga dilakukan melalui pemasangan perangkap (cage trap dan camera trap) khususnya mamalia kecil seperti kelompok tikus, tupai juga kamera trap sebanyak 2 unit pada masing-masing lokasi. Selanjutnya dilakukan pula wawancara dengan masyarakat terkait jenis dan sebaran untuk memastikan jenis marsupialia yang tidak teramati secara langsung. Wawancara dimaksud secara khusus terhadap 3 tokoh masyarakat dan perwakilan 12 masyarakat pada ketiga kampung di wilayah studi yang mengetahui dan atau terkait langsung dengan pengelolaan satwa liar (pemanfaatan). Data hasil penelitian yang terdiri atas jenis dan penyebaran selanjutnya dianalisis secara deskriptif dan tampilkan dalam bentuk tabel dan gambar.

\section{HASIL DAN PEMBAHASAN}

\section{Jenis Marsupialia}

Areal hutan rencana pembangunan perkebunan pala Kopermas Kami Nasey memiliki keanekeragaman jenis mamalia khususnya marsupialia yang cukup tinggi.
Hal tersebut terlihat dari data hasil inventarisasi sebagaiman 16 jenis marsupilia yang diidentifikasi. Data tersebut jauh lebih banyak dibandingkan dengan areal POD I Genting Oil Kasuri di Distrik Sumuri Kabupaten Teluk Bintuni yang mengidentifikasi 10 jenis marsupialia di kawasan ini (Krey dkk. 2019). Demikian halnya kawasan TWA Gunung Meja yang dilaporkan sebanyak 11 jenis mamalia terdapat di wilayah ini (Manusawai dan Leonard 2015). Kondisi tersebut menggambarkan bahwa kawasan hutan ini memiliki daya dukung habitat yang cukup baik dan menjadi ciri dari hutan dataran rendah yang kaya akan berbagai kebutuhan satwa. Menurut Sinery (2006) dan Sinery (2015), hutan pulau Numfor, hutan TWA Gunung Meja dan umumnya hutan dataran rendah merupakan habitat yang baik bagi satwa karena menyediakan berabagai jenis pakan termasuk tempat beraktivitas.

\section{Deskripsi Jenis}

Kehadiran jenis sebagaimana tergambar melalui distribusi individu yang ditemukan pada keempat lokasi pengamatan adalah berbeda-beda. Keempat lokasi tersebut berturut-turut adalah hutan sekitar Kampung Werabur sebanyak 8 spesies, hutan pada lokasi penanaman bibit pala sebanyak 13 spesies, hutan sekitar gunung Maskeri sebanyak 16 spesis dan hutan dataran rendah dan hutan rawa di sekitar Kampung Idor dijumpai 12 spesies. Beberapa spesies yang sama dapat dijumpai pada empat lokasi, namun ada pula yang hanya dijumpai pada satu lokasi. Jika dilihat dari jumlah spesies yang ditemukan, dapat dinilai lebih beragam pada hutan sekitar gunung Maskeri, hutan dataran rendah dan hutan 
rawa di dekat kampung Idor dan lokasi penanaman bibit pala dibanding hutan di dekat kampung Werabur. Hal ini menunjukkan perbedaan kualitas habitat sehingga menjadi penentu konsentrasi populasi beberapa jenis satwa. Famili terbanyak pada ordo Marsupialia sebanyak 8 famili.

Berdasarkan hasil pengamatan, wawancara dan studi pustaka, diduga lebih dari 16 jenis marsupial terdapat di kawasan hutan ini, namun demikian melalui penelitian ini berhasil diidentifikasi enam jenis jenis mamalia berkantung. Tiga jenis diantaranya dilindungi sesuai Permen LHK P106/2018 dan juga terdaftar dalam IUCN dan CITES (Appendix 2).

Kanguru pohon cenderawasih (Dendrolagus ursinus) merupakan jenis endemik kepala burung dan menyebar di Pegunungan Arfak dan Semenanjung Fakfak. Menurut Flannery (1995), bahwa spesies ini dapat dijumpai dari 0 sampai 2.300 mdpl pada habitat hutan primer. Jenis ini ditemukan masyarakat di sekitar Gunung Maskeri beberapa hari sebelum kegiatan penelitian. Kanguru pohon bereproduksi sepanjang tahun dan menyusui anak selama 5 - 6 bulan. Jenis ini mempunyai ciri fisiologis yang disebut diapause embrio atau kelahiran tertunda. Hal ini memungkinkan betina untuk segera kawin lagi setelah melahirkan atau waktu masih ada anak dalam kantung bayi. Akan tetapi, perkembangan telur yang telah dibuahi itu ditunda sampai anak hampir mengakihiri kehidupan dalam kantung (ditinggalkan). Ketidakberadaan anak dalam kantung mencetuskan perkembangan lanjut sampai kelahiran. Berbeda dengan landak papua (Ekidna), sifat sosial dan senang berkumpul kanguru pohon merupakan salah satu penyebab penyusutan populasi jenis ini. Perburuan kanguru yang berhasil mungkin dapat membunuh seluruh anggota satu kelompok keluarga, bukan hanya seekor binatang (Petocz 1994). Kanguru pohon cenderawasih masuk Red list kategori Vulnerable IUCN dengan populasi menurun di alam, selain itu Permen LHK P.106/2018.

Walabi biasa hutan (Dorcopsis muelleri) atau kanguru tanah menempati dataran rendah bagian Barat mainland Papua serta pulau Misool, Salawati, dan Yapen (Petocz 1994; Flannery 1995). Penyebaran hewan ini sangat luas dan dapat ditemukan dekat pemukiman manusia. Matayang lebar merupakan mata khas hewan nokturnal, namun demikian hewan ini dapat aktif selama sebagian siang hari pada waktu adanya sinar matahari. Jenis ini memiliki jumlah populasi yang sangat besar di wilayah ini, namun hanya dijumpai jejak kaki pada saat pengamatan lapangan. Untuk memburu walabi masyarakat harus berjalan cukup jauh dari kampung dan atau jalan utama, karena semakin jauh populasi ini akibat aktivitas masyarakat termasuk berburu. Walaupun populasi yang besar di alam, hewan ini di beberapa daerah memiliki ancaman yang serius akibat perburuan untuk dikonsumsi. Demikian hanya dengan kehilangan habitat akibat konversi hutan untuk lahan pertanian dan kebun masyarakat juga memicu penurunan populasi jenis ini.

Kuskus bertotol (Spilocuscus maculatus) banyak diminati oleh masyarakat karena keunikan bentuk dan warna rambut yang indah. Selain dagingnya dikonsumsi, kulitnya dapat dijadikan hiasan/pajangan yang menarik di dalam rumah. Jenis ini sangat umum dan dapat dijumpai pada ketinggian 0 
sampai 1.200 mdpl di hutan primer maupun hutan sekunder di seluruh Papua, kecuali areal savanna tidak ditemukan (Flannery 1995). Kuskus totol hitam (Spilocuscus rufoniger) memiliki warna mencolok yang membedakannya dari kedua jenis lainnya pada marga Spilocuscus. Jantan memiliki pola warna dilukiskan sebagai penempatan warna coklat kemerahan pada latar belakang putih dan warna hitam pada latar belakang coklat. Bulu betina lebih terang dan didominasi warna putih sampai kuning daging. Kuskus timur (Phalanger orientalis) merupakan jenis kuskus yang tidak bertotol. Sama halnya dengan Spilocuscus maculatus, spesies ini diminati masyarakat untuk dikonsumsi. Kuskus timur tersebar di Papua, namun belum dilaporkan untuk wilayah selatan Papua. Penyebarannya dari 0 sampai $1.500 \mathrm{mdpl}$, dan dapat dijumpai di hutan primer, hutan sekunder, dan juga bekas kebun. Jenis ini juga dijumpai pada pulau di wilayah Teluk Wondama seperti Roon dan beberapa pulau lainnya. Pada tahun 2017 dan 2018 ditemukan masing-masing 1 dan 2 individu jenis kuskus ini oleh masyarakat yang dibawah ke wilayah Wasior. Menurut Sinery (2015) kuskus jenis ini lebih adaptif terhadap perubahan habitat sehingga dapat ditemukan di hutan sekunder dan kebun masyarakat, selain di hutan primer. Kuskus tanah adalah kuskus terbesar kedua setelah Spilocuscus maculatus, berat jantan dapat mencapai 5 kg. Sebutan "kuskus tanah" karena jenis ini hidup di lubang-lubang tanah, cela bebatuan atau di bawah reruntuhan batu. Dikenal juga kuskus gigi besar sebagai sinonim gigi premolar akhir yang besar dan menjadi satu indikator dalam identifikasi lewat anatomi jenis ini. Warna bulu coklat mirip wool, kadang terlihat efek keperakan, dorsal coklat atau kelabu dan ventral agak putih. Warna ekor hitam kadang disertai warna putih di ujung ekor, permukaan bawah ekor mirip parutan kayu (kertas pasir), berakhir lebih mencolok dan lonjong ke ujung ekor secara teratur seperti ekor Phalanger orientalis (Petocz 1994; Flannery 1995). Ketiga jenis kuskus ini terdapat di huta. Ketiga jenis ini dilindungi sesuai PerMen LHK P.106/2018 tentang Jenis Tumbuhan dan Satwa yang dilindungi dan masuk Appendix II CITES.

Dactylopsila palpator adalah possum yang tersebar luas di wilayah kepala burung, New Guinea tengah dan Semenanjung Huon dan diduga memiliki populasi besar di alam. Data populasi hewan ini belum diketahui, kadang hewan ini diburu penduduk untuk dimakan atau diambil kulitnya, namun untuk menemukannya sangat susah, sehingga perburuan tidaklah menjadi ancaman yang signifikan. Berdasarkan hasil wawancara speses ini sering diburu oleh masyarakat setempat unruk dikonsusmsi dan juga kulit jenis ini dijadikan hiasan.

\section{DAFTAR PUSTAKA}

Flannery T. 1995. Possums of the world. A Monograph of the Phalangeroidea. Geo Production Pty Ltd, Australia.

IUCN Red List of Threatened Species, Version 2010.1. www.iucnredlist.org. Downloaded on 4 August 2010.

Krey K, Warmetan H, Mamboai H, Parenden D, Lekitoo K, Tukayo R, Ronsumbre A, Hematang F, Koromari B, Tambing Y, Dubri Y, Sinery A. 2019. Kasuri block high conservation value. Deepublish, Yogyakarta.

Manusawai J dan Leonard D. 2015. Potensi dan strategi pengelolaan 
Taman Wisata Alam Gunung Meja. Deepublish, Yogyakarta.

Odum P. 1993. Fundamentals of ecology. 3rd ed. Gajah Mada Univ. Press, Yogyakarta [Indonesian].

Petocz RG. 1994. Terrestrial mammalia of Irian Jaya. PT Gramedia Pustaka Utama, Jakarta. [Indonesian].

Petocz RG. 1987. Konservasi alam dan pembangunan di Irian Jaya. Jakarta: Pustaka Grafitipers.
Primack, Supriatna, Indrawan dan Kramadibrat. 2000. Biologi konservasi. Yayasan Obor Indonesia. Sinery AS 2006. Species of cuscus in Taman Wisata Gunung Meja Manokwari Regency, West Irian Jaya. Biodiversitas, 7 (2): 175-180.

Sinery AS. 2015. Management strategies of cuscus on the Numfor Island. Deeppublish, Yogyakarta. [Indonesia] 
Lampiran 1. Jenis- Jenis Mamalia Pada Areal Rencana Pembangunan Perkebunan Pala Kopermas Kami Nasey Distrik Nikiwar dan Distrik Idor Pada Kabupaten Teluk Wondama dan Kabupaten Teluk Bintuni.

\begin{tabular}{|c|c|c|c|c|c|c|c|c|c|c|}
\hline \multirow{2}{*}{$\begin{array}{c}\text { Ordo } \\
\text { (Marsupialia) }\end{array}$} & \multicolumn{2}{|l|}{ Nama } & \multicolumn{4}{|c|}{ Lokasi } & \multirow{2}{*}{ Endemik } & \multirow{2}{*}{ IUCN } & \multirow{2}{*}{ CITES } & \multirow{2}{*}{$\begin{array}{c}\text { P.106/ } \\
2018\end{array}$} \\
\hline & Jenis & English & 1 & 2 & 3 & 4 & & & & \\
\hline \multirow{2}{*}{ Dasyuridae } & Antechinus nosa (Jentink, 1911b) & Long-nosed Anthecinus & & * & * & $*$ & $\mathrm{~N}$ & $\mathrm{LC}$ & & \\
\hline & Dasyurus albopunctatus (Schlegel, 1880) & New Guinea Quoll & & & $*$ & & $\mathrm{~N}$ & NT & & \\
\hline \multirow{2}{*}{ Peroryctidae } & Echymipera kalubu (Lesson,1828) & Common Echymipera & $*$ & $*$ & $*$ & $*$ & $\mathrm{~N}$ & $\mathrm{LC}$ & & \\
\hline & E. rufescens (Peters \& Doria 1875) & Long-nosed Echymipera & & * & $*$ & $*$ & $\mathrm{~N}$ & $\mathrm{LC}$ & & \\
\hline \multirow{3}{*}{ Macropodidae } & Dorcopsis muelleri (Schlegel, 1866b) & Brown Dorcopsis & $*$ & $*$ & $*$ & $*$ & $\mathrm{~N}$ & $\mathrm{LC}$ & & \\
\hline & Dendrolagus inustus (Muller,1840) & Grizzled Tree-kangaroo & & & $*$ & & $\mathrm{~N}$ & $\mathrm{VU}$ & II & $\mathrm{L}$ \\
\hline & Dendrolagus ursinus (Muller,1840) & Vogelkop Tree-kangaroo & & & * & & $\mathrm{N}$ & VU & II & $\mathrm{L}$ \\
\hline \multirow{3}{*}{ Phalangeridae } & Spilocuscus maculatus (Desmarest,1818) & Common Spotted Cuscus & & $*$ & * & $*$ & N.M & LC & II & $\mathrm{L}$ \\
\hline & Spilocuscus rufoniger (Zimara, 1937) & Black Spotted Cucus & & $*$ & $*$ & $*$ & $\mathrm{~N}$ & $\mathrm{CR}$ & II & $\mathrm{L}$ \\
\hline & Phalanger orientalis (Pallas, 1766) & Northern Brown Cuscus & $*$ & $*$ & $*$ & $*$ & N.M & $\mathrm{LC}$ & II & \\
\hline Acrobatidae & Distoechurus pennatus (Peters,1874) & Feather-tailed Possum & $*$ & $*$ & $*$ & $*$ & $\mathrm{~N}$ & $\mathrm{LC}$ & & \\
\hline \multirow{3}{*}{ Petauridae } & Petaurus breviceps (Waterhouse,1838) & Sugar Glider & $*$ & $*$ & $*$ & $*$ & $\mathrm{~N}$ & $\mathrm{LC}$ & & \\
\hline & Dactylopsila palpator (Milne Edwards, 1888) & Long-fingered Triok & & * & $*$ & & $\mathrm{~N}$ & $\mathrm{LC}$ & & \\
\hline & Dactylopsila trivirgata (Gray 1858a) & Striped Possum & $*$ & * & $*$ & $*$ & $\mathrm{~N}$ & $\mathrm{LC}$ & & \\
\hline \multicolumn{3}{|c|}{ Jumlah } & 6 & 11 & 14 & 10 & & & & \\
\hline
\end{tabular}

Keterangan : $\quad 1=$ Hutan Sekunder, 2 = Areal Rencana Persemaian,

3 = Kawasan Karts Gunung Maskeri, 4 = Hutan Rawa /Dataran Rendah (Sekitar Goa Karatobi dan Batu Nassey)

$\mathrm{N}=$ New Guinea, NM = New Guinea Molucsas, Australia

$\mathrm{LC}=$ Least Concern, $\mathrm{NT}=$ Near Threatened, $\mathrm{VU}=$ Vulnerable, $\mathrm{CR}=$ Criticaly Endangered 